\title{
Microbiological analysis of the population of extremely haloalkaliphilic sulfur-oxidizing bacteria dominating in lab-scale sulfide-removing bioreactors
}

\author{
D. Y. Sorokin • P. L. F. van den Bosch • B. Abbas • \\ A. J. H. Janssen • G. Muyzer
}

Received: 14 May 2008 /Revised: 26 June 2008 / Accepted: 26 June 2008 /Published online: 2 August 2008

(C) The Author(s) 2008

\begin{abstract}
Thiopaq biotechnology for partial sulfide oxidation to elemental sulfur is an efficient way to remove $\mathrm{H}_{2} \mathrm{~S}$ from biogases. However, its application for high-pressure natural gas desulfurization needs upgrading. Particularly, an increase in alkalinity of the scrubbing liquid is required. Therefore, the feasibility of sulfide oxidation into elemental sulfur under oxygen limitation was tested at extremely haloalkaline conditions in lab-scale bioreactors using mix sediments from hypersaline soda lakes as inoculum. The
\end{abstract}

Nucleotide sequence accession numbers: The GenBank/EMBL accession numbers of the $16 \mathrm{~S}$ rRNA gene sequence determined in this study are EU709849-EU709878.

Electronic supplementary material The online version of this article (doi:10.1007/s00253-008-1598-8) contains supplementary material, which is available to authorized users.

\section{Y. Sorokin $(\varangle)$}

Winogradsky Institute of Microbiology,

Russian Academy of Sciences,

Prospect 60-let Octyabrya 7/2,

117811 Moscow, Russia

e-mail: soroc@inmi.host.ru

D. Y. Sorokin $\cdot$ B. Abbas $\cdot$ G. Muyzer

Environmental Biotechnology Group, Department of Biotechnology,

Delft University of Technology,

Julianalaan 67 ,

2628 BC Delft, The Netherlands

P. L. F. van den Bosch • A. J. H. Janssen

Sub-Department of Environmental Technology,

Wageningen University,

6700 EV Wageningen, The Netherlands

A. J. H. Janssen

Shell Global Solutions International,

B.V. P.O. Box 38000, 1030 BN Amsterdam, The Netherlands microbiological analysis, both culture dependent and independent, of the successfully operating bioreactors revealed a domination of obligately chemolithoautotrophic and extremely haloalkaliphilic sulfur-oxidizing bacteria belonging to the genus Thioalkalivibrio. Two subgroups were recognized among the isolates. The subgroup enriched from the reactors operating at $\mathrm{pH} 10$ clustered with Thioalkalivibrio jannaschii-Thioalkalivibrio versutus core group of the genus Thioalkalivibrio. Another subgroup, obtained mostly with sulfide as substrate and at lower $\mathrm{pH}$, belonged to the cluster of facultatively alkaliphilic Thioalkalivibrio halophilus. Overall, the results clearly indicate a large potential of the genus Thiolalkalivibrio to efficiently oxidize sulfide at extremely haloalkaline conditions, which makes it suitable for application in the natural gas desulfurization.

Keywords Thiopaq · Sulfide removal · Haloalkaliphilic · Sulfur-oxidizing bacteria (SOB) - Soda lakes · Polysulfide . Thioalkalivibrio

\section{Introduction}

The presence of $\mathrm{H}_{2} \mathrm{~S}$ in fuel gases causes many environmental and technical problems demanding its removal before combustion. Usually, it is done by a catalytic oxidation. An alternative bioprocess based on lithoautotrophic sulfide-oxidizing bacteria (SOB) as a catalyst has been developed and successfully applied at full scale in The Netherlands for biogas desulfurization (Buisman et al. 1990; Janssen et al. 1995, 1999). The major principle of the Thiopaq technology is regulation of sulfide oxidation at the level of elemental sulfur by low redox potential, which provides two advantages over the complete oxidation to 
sulfate: (1) The oxidation does not generate protons but regenerates hydroxyl ions, thereby allowing to save on caustic absorbent; (2) formation of elemental sulfur allows easy separation of the final oxidation product and recirculation of the liquid phase. In case of biogas, the bioprocess is performed at relatively low salt concentrations and $\mathrm{pH}$, i.e., at $0.5 \mathrm{M}$ total $\mathrm{Na}^{+}$and $\mathrm{pH} 8.2-8.5$, with bicarbonate as the dominant anion in solution. At these conditions, marinetype SOB, such as Halothiobacillus neapolitanus W5 (Visser 1997), function very well. However, for the removal of $\mathrm{H}_{2} \mathrm{~S}$ from high-pressure natural gas and sour gas streams produced in the petrochemical industry, the total alkalinity must be substantially increased to make scrubbing process more efficient. This dictates a shift in a type of biocatalyst from neutrophilic marine SOB to natronophilic (sodaphilic), highly salt tolerant SOB (Banciu et al. 2004a; van den Bosch et al. 2007, 2008). Such SOB have recently been discovered in the sediments of hypersaline soda lakes (Sorokin and Kuenen 2005; Sorokin et al. 2006a). One out of three genera of haloalkaliphilic SOB described so far, the genus Thioalkalivibrio, is characterized by the ability to grow in saturated soda brines containing up to $4 \mathrm{M}$ total $\mathrm{Na}^{+}$and $\mathrm{pH}$ from 7 to 10.5. All but one out of nine described species of this genus are obligatory alkaliphilic and soda-philic; that is, they can only grow in carbonate brines and at a $\mathrm{pH}$ above 8 . A single species, Thioalkalivibrio halophilus, is a facultative halophile capable of growth at neutral $\mathrm{pH}$ in $\mathrm{NaCl}$ brines as well as in soda brines at $\mathrm{pH}$ 10 (Banciu et al. 2004b). All previously described high salttolerant Thioalkalivibrio strains were obtained from the enrichments with thiosulfate as substrate and at high redox potential, since batch cultivation at low redox potential with sulfide as an electron donor is much more complicated. Therefore, such organisms might be unsuitable for application in the Thiopaq process module, where the redox potential is as low as $-350 \mathrm{mV}$ and sulfide/polysulfide is the actual electron donor.

This paper describes results of a microbiological investigation of lab-scale bioreactors oxidizing sulfide/polysilfide at $\mathrm{pH} 8.5-10$ and a salt content of $2-3 \mathrm{M} \mathrm{Na}^{+} / \mathrm{K}^{+}$. It is shown that the populations were dominated by extremely salt-tolerant alkaliphilic SOB, represented by two subgroups of the genus Thioalkalivibrio.

\section{Materials and methods}

Inoculum for the bioreactors

Surface sediment samples $(0-10 \mathrm{~cm})$ were obtained from hypersaline soda lakes in northeastern Mongolia, southwestern Siberia, and Wadi al Natrun in Egypt. Eight to 12 samples from individual lakes in each region were com- bined into a single pool. The $\mathrm{pH}$ of the brines varied from 9.2 to 10.6 , total salt concentration from 60 to $400 \mathrm{~g} \mathrm{l}^{-1}$, and total soluble alkalinity from 0.05 to $3 \mathrm{M}$.

\section{Bioreactors}

Two types of lab-scale bioreactors were used for oxidation of sulfide at oxygen-limited conditions. One was a 5-L gaslift column (FBR) fed by $\mathrm{H}_{2} \mathrm{~S}$ gas where oxygen supply was controlled by a redox electrode (vs $\mathrm{Ag} / \mathrm{AgCl}$; van den Bosch et al. 2007, 2008). Another type was a 1-L stirred tank reactor (SL-BR) where sodium sulfide was fed in sequential fed-batch mode (1 $\mathrm{mM}$ shots) and oxygen was supplied by limited diffusion through a loop from silicon tubing (Supplementary Fig. 1). The major difference between these two types of bioreactors was the concentration of polysulfide. In the FBR, it was generally maintained at a relatively low level of $100 \mu \mathrm{M}$ sulfane using redox control. The fraction of free sulfide as compared to polysulfide was minimal at $\mathrm{pH} 10$ and increased toward $\mathrm{pH}$ decrease. In the SL-BR, the concentration of polysulfide reached $1 \mathrm{mM}$ right after addition of sulfide due to a rapid spontaneous reaction with sulfur formed during the previous stage, decreasing gradually to zero due to biological activity of the SOB. Therefore, the latter conditions were selective for high polysulfide/sulfide resistance and polysulfide as a substrate.

\section{Operating conditions}

The duplicate FBR were run during 2 years at variable modes at $\mathrm{pH}$ starting from 10.1 and ending at 8.8 (Table 1). The redox potential was maintained most of the time below -390 $\mathrm{mV}$ (vs $\mathrm{Ag} / \mathrm{AgCl}$ ). The mineral medium was based on bicarbonate/carbonate buffer containing $70 \% \mathrm{~K}^{+}$and $30 \%$ $\mathrm{Na}^{+}, 2 \mathrm{M}$ in total. The presence of so much potassium is certainly unusual and never occurs in natural soda lakes. The reason behind employing such an unusual buffer is the much higher solubility of potassium carbonates as compared to sodium carbonates, especially when $\mathrm{pH}$ is decreased below 9 and bicarbonate is the dominant anion. Our preliminary tests with extremely haloalkaliphilic cultures of the genus Thioalkalivibrio demonstrated that many strains can withstand up to $50 \%$ replacement of $\mathrm{Na}^{+}$by $\mathrm{K}^{+}$at $2 \mathrm{M}$ total cation in the form of carbonates, and a few strains even tolerated $90 \%$ replacement. This is in contrast to the neutrophilic halophilic SOB, which cannot grow already at $30 \%$ replacement of $\mathrm{NaCl}$ by $\mathrm{KCl}$ (Sorokin 2008). The N source in the bioreactors was urea. A more detailed description of these bioreactors is given elsewhere (van den Bosch et al. 2007, 2008). The duplicate 1-L SL-BRs were run within 2 months at $1.2-3.0 \mathrm{M}$ of $\mathrm{K} / \mathrm{Na}$ carbonates, $70 \% \mathrm{~K}$, and $\mathrm{pH}$ 10.1. The $\mathrm{N}$ source was ammonia. 
Table 1 Reactors and isolates data

\begin{tabular}{|c|c|c|c|c|c|c|c|c|}
\hline \multicolumn{4}{|l|}{ Bioreactors } & \multicolumn{5}{|c|}{ Isolation of the dominant $\mathrm{SOB}$} \\
\hline \multirow[t]{2}{*}{ Type } & \multirow[t]{2}{*}{ Mode } & \multirow[t]{2}{*}{$\mathrm{pH}$} & \multirow[t]{2}{*}{$\mathrm{K}^{+} / \mathrm{Na}^{+}(\mathrm{M})$} & \multicolumn{2}{|c|}{ Viable count } & \multirow[t]{2}{*}{ Strain } & \multirow[t]{2}{*}{ Substrate } & \multirow[t]{2}{*}{ Sulfur autotrophy } \\
\hline & & & & Thio & $\mathrm{HS}^{-}$ & & & \\
\hline \multirow[t]{17}{*}{ 5-L gas-lift column } & \multirow[t]{10}{*}{ Chemostat } & \multirow[t]{7}{*}{$10.0-10.1$} & \multirow[t]{10}{*}{2.0} & \multirow[t]{7}{*}{$10^{10}$} & \multirow[t]{7}{*}{$10^{11}$} & ALR1-1 & Thio & + \\
\hline & & & & & & ALR1-2 & Thio & + \\
\hline & & & & & & ALR 2 & $\mathrm{HS}^{-}$ & + \\
\hline & & & & & & ALR6 & Thio & + \\
\hline & & & & & & ALR7 & $\mathrm{HS}^{-}$ & + \\
\hline & & & & & & ALR8 & $\mathrm{HS}^{-}$ & + \\
\hline & & & & & & ALR9 & $\mathrm{HS}^{-}$ & + \\
\hline & & \multirow[t]{3}{*}{9.7} & & \multirow[t]{3}{*}{$10^{8}$} & \multirow[t]{3}{*}{$10^{10}$} & ALR3 & Thio & + \\
\hline & & & & & & ALR4 & $\mathrm{HS}^{-}$ & + \\
\hline & & & & & & ALR5 & $\mathrm{HS}^{-}$ & + \\
\hline & \multirow[t]{7}{*}{ Fed-batch } & \multirow[t]{3}{*}{9.8} & & \multirow[t]{3}{*}{$10^{8}$} & \multirow[t]{3}{*}{$10^{11}$} & ALRU1 & Thio & + \\
\hline & & & & & & ALRU2 & $\mathrm{HS}^{-}$ & + \\
\hline & & & & & & ALRU3 & $\mathrm{HS}^{-}$ & + \\
\hline & & $9.5^{\mathrm{a}}$ & & $10^{8}$ & $10^{8}$ & ALR10 & Thio & + \\
\hline & & \multirow[t]{3}{*}{$8.8^{\mathrm{b}}$} & & \multirow[t]{3}{*}{$10^{8}$} & \multirow[t]{3}{*}{$10^{10}$} & ALR14 & $\mathrm{HS}^{-}$ & + \\
\hline & & & & & & ALR15 & $\mathrm{HS}^{-}$ & - \\
\hline & & & & & & ALR16-ALR20 & $\mathrm{HS}^{-}$ & + \\
\hline \multirow{9}{*}{$\begin{array}{l}\text { 1-L silicon-loop } \\
\text { reactor }\end{array}$} & \multirow[t]{9}{*}{ Sequential batch } & \multirow[t]{9}{*}{10.1} & 2.0 & \multirow[t]{2}{*}{ nd } & nd & ALBR1 & Thio & + \\
\hline & & & & & & ALBR2 & $\mathrm{HS}^{-}$ & + \\
\hline & & & $3.0^{\mathrm{c}}$ & $10^{5}$ & $10^{6}$ & ALBR3 & Thio & + \\
\hline & & & & & & ALBR4 & Thio & + \\
\hline & & & & & & ALBR X1 & Thio & + \\
\hline & & & & & & ALBR X2 & Thio & + \\
\hline & & & & & & ALBR5 & $\mathrm{HS}^{-}$ & + \\
\hline & & & & & & ALBR6 & $\mathrm{HS}^{-}$ & + \\
\hline & & & & & & ALBR X3 & $\mathrm{HS}^{-}$ & + \\
\hline
\end{tabular}

${ }^{\mathrm{a}}$ Correspond to FBR1

${ }^{\mathrm{b}}$ Correspond to FBR2

${ }^{\mathrm{c}}$ Correspond to SL-BR2

Isolation and cultivation of pure cultures of extremely haloalkaliphilic SOB

Two approaches were used for the enrichment and isolation of pure cultures of haloalkaliphilic SOB. One was based on using thiosulfate as substrate $(20 \mathrm{mM})$, which is stable at aerobic conditions. Alternatively, sulfide $(2 \mathrm{mM})$ was used as a substrate. Use of sulfide is much more difficult because of its volatility, toxicity, and spontaneous oxidation. The former effects, however, are reduced at highly alkaline $\mathrm{pH}$, while the spontaneous oxidation was reduced by a ten times decrease in trace metal content and the use of only $1 \%$ oxygen in the gas phase. To standardize the enrichment procedure, the same conditions were also used in the thiosulfate enrichments. The liquid mineral medium used for enrichment and isolation contained carbonate buffer with $2 \mathrm{M} \mathrm{K} / \mathrm{Na}(70 \% \mathrm{~K}), \mathrm{pH} 10,1 \mathrm{~g} / \mathrm{L}$ of $\mathrm{K}_{2} \mathrm{HPO}_{4}$, and $4 \mathrm{mM}$ of either $\mathrm{NH}_{4} \mathrm{Cl}$ or urea. After sterilization, the medium was supplemented with trace metals (Pfennig and Lippert 1966), $1 \mathrm{mM} \mathrm{MgCl}_{2}$, and a sulfur substrate. Serial dilutions were incubated at $30^{\circ} \mathrm{C}$ in $20-\mathrm{mL}$ Hungate tubes with $2 \mathrm{~mL}$ medium and a headspace containing $1 \% \mathrm{O}_{2}$ in argon. When turbidity appeared in a highest dilution, it was plated into a solid agar medium of the same composition. The plates were incubated in closed jars (3 L) under the atmosphere of argon containing $1 \% \mathrm{O}_{2}$. In case of sulfide enrichments, the plates did not contain any substrates. Instead, $4 \mathrm{~mL}$ of $1 \mathrm{M}$ sodium sulfide solution was placed into the jar in a $10-\mathrm{mL}$ vial. During the prolonged incubation (2-4 weeks), $\mathrm{H}_{2} \mathrm{~S}$ entered the gas phase and was absorbed by the alkaline agar creating optimal conditions for sulfide-utilizing SOB. Dominating colony types were picked under the binocular and placed into the liquid medium. The purity of the culture was checked by repeated plating.

Metabolic profiles of the reactor biomass and pure cultures

The activity and the stoichiometry of oxidation of various sulfur compounds was studied with an oxygen electrode 
using washed cells as described previously (Banciu et al. 2004b). The $\mathrm{pH}$ dependence was examined at $2 \mathrm{M}$ total $\mathrm{Na}^{+}$, using the following buffers: for $\mathrm{pH}$ 6-8, $0.1 \mathrm{M}$ 4-(2hydroxyethyl)-1-piperazineethanesulfonic acid and $\mathrm{NaCl}$; for $\mathrm{pH} 8-11$, a mixture of sodium bicarbonate/sodium carbonate containing $0.1 \mathrm{M} \mathrm{NaCl}$. To study the influence of salt concentration, sodium carbonate buffer with $\mathrm{pH} 10$ containing 0.1 and $4.0 \mathrm{M}$ of total $\mathrm{Na}^{+}$was applied. All buffers contained $50 \mathrm{mM} \mathrm{K}^{+}$and $1 \mathrm{mM} \mathrm{Mg}^{2+}$. Cell membranes were obtained by ultracentrifugation of the sonified cells at $144,000 \times g$ for $2 \mathrm{~h}$ (Beckman). The membranes were resuspended in soda buffer at $\mathrm{pH} 9$ containing $0.5 \mathrm{M}$ total $\mathrm{Na}^{+}$and used to measure several enzyme activities. Cytochrome $c$ oxidase was measured by the rate of oxidation of $1 \mathrm{mM} N, N, N^{\prime}, N^{\prime}$-tetramethyl $p$-phenylenediamine (TMPD) spectrophotometrically at $610 \mathrm{~nm}$. Sulfide-quinon reductase (SQR) activity was determined in a discontinuous assay of anaerobic decyl-ubiquinondependent oxidation of sulfide ( $0.2 \mathrm{mM}$ each). Cytochrome $c$ content in the membranes was estimated from spectroscopic measurements of dithionite-reduced minus air-oxidized preparations using UV-visible diod-array spectrophotometer (Vectra 8453, HP, Amsterdam) and molar absorbance coefficient $E_{550} 20 \mathrm{mM} \mathrm{cm}^{-1}$.

\section{Analytical procedures}

Chemical analysis of sulfur (sulfide, sulfur, thiosulfate, and sulfite) and nitrogen (nitrite and ammonium) compounds and cell protein were performed as described previously (Sorokin et al. 2001; Banciu et al. 2004b). Sulfane sulfur atoms of polysulfide were analyzed in the same way as free sulfide, i.e., after precipitation as $\mathrm{ZnS}$. Zero-valent sulfur in polysulfide was analyzed in the same way as free sulfur (i.e., by cyanolysis of acetone extract) after decomposition of polysulfide molecules by acid treatment. Total protein comparison of the isolates and the reactor biomass was performed using $5-15 \%$ gradient sodium dodecyl sulfate polyarcylamide gel electrophoresis (SDS-PAGE) according to Laemmli (1970). Repetitive-sequence-based polymerase chain reaction (REP-PCR) fingerprinting comparison of the SOB isolates was performed with the GTG5 primer set as described previously (Foti et al. 2006).

Genetic and phylogenetic analysis

Genomic deoxyribonucleic acid (DNA) was extracted from the cell pellet using the UltraClean Soil DNA Extraction Kit (MoBio Laboratories, USA), following the manufacturer's instructions. For the pure cultures, the nearly complete 16S ribosomal ribonucleic acid (rRNA) gene was obtained using general bacterial primers GM3f (5'AGAGTtTGATCCTGGCTCAG-3') and GM4r (5'-
TAСГГТTAC-CTTGTTACGACTT-3'). For the denaturing gradient gel electrophoresis (DGGE) analysis, partial amplification with a primer pair $341 \mathrm{~F}+\mathrm{GC} / 907 \mathrm{R}$ was employed (Schäfer and Muyzer 2001). DGGE was performed as described by Muyzer et al. (1993), using a denaturing gradient of $20-35 \%$ to $60-70 \%$ denaturants in $8 \%$ polyacrylamide gel. Individual bands were excised, reamplified, and run again on a denaturing gradient gel to check their purity. PCR products for sequencing were purified using the Qiaquick PCR purification kit (QIAGEN, The Netherlands). The sequences were first compared with sequences stored in GenBank using the BLAST algorithm (http://www.ncbi.nlm.nih.gov/BLAST). Subsequently, the sequences were imported into the ARB software program (Ludwig et al. 2004), automatically aligned, and added to a phylogenetic tree using the Quick-add tool. Subtrees were then built using the neighbor-joining algorithm with automatic selected correction settings.

\section{Results}

Catalytic properties of the bioreactor biomass

Respiration profiles for different sulfur compounds were determined with washed cells directly from the bioreactors and used to characterize the activity and $\mathrm{pH} / \mathrm{salt}$ response of the dominant SOB populations. A general trend could be seen that sulfide and, in case of the SL-BR reactors, polysulfide were much better respiratory substrates for the mixed SOB population in the reactors than thiosulfate (Fig. 1a). This is not usually the case with the SOB dominating fully aerobic conditions (Sorokin et al. 2006a). Sulfide/polysulfide specialization indicates that there should be a different pathway for oxidation of these highly reduced electron donors as compared to thiosulfate oxidation. One of the specialized components of such a pathway might be sulfide-quinone reductase - a flavin-containing enzyme oxidizing sulfide to elemental sulfur with quinones as electron acceptors (Griesbeck et al. 2000). We found a relatively high activity of this enzyme in the biomass of the analyzed bioreactors (Fig. 1b). Another parameter characteristic for a highly active respiratory chain in aerobic chemolithoautotrophs is the activity of cytochrome $c$ oxidase together with the presence of a high-potential cytochrome $c$ pool. This pair is responsible for the terminal delivery of the electrons obtained during oxidation of electron donor to oxygen. Comparison of the three reactor samples demonstrated that only in FBR2 ( $\mathrm{pH} 8.8$ ), it was at a level normal for aerobic haloalkaliphilic SOB (personal data on pure cultures), while in SL-BR2 (pH 10) and FBR1 (pH 9.5), the cytochrome $c$ oxidase had a low specific activity. This might be connected to the condition of extremely low 

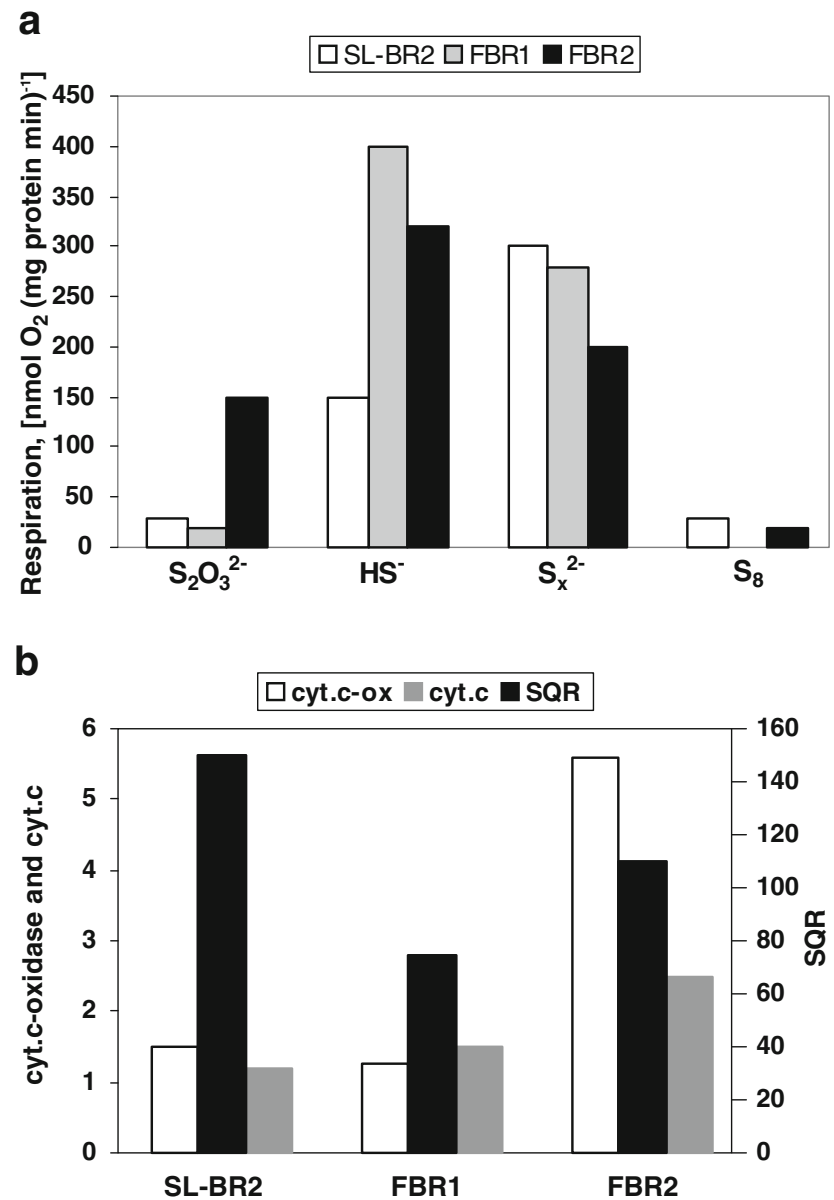

Fig. 1 Metabolic activity of SOB biomass from sulfide-oxidizing bioreactors (see Table 1). a Respiratory activity of whole cells with different sulfur substrates at $\mathrm{pH} 10$ and $2 \mathrm{M}$ total $\mathrm{Na} / \mathrm{K}$ (carbonates). (b) Respiratory enzyme parameters in cell membranes: cytochrome $c$ oxidase, $\mu \mathrm{mol}$ TMPD (mg protein min) ${ }^{-1}$ at $\mathrm{pH} 9$, cytochrome $c$ content, nmol (mg protein min) $)^{-1}$, and SQR activity, $\mathrm{nmol} \mathrm{HS}^{-}(\mathrm{mg} \text { protein } \mathrm{min})^{-1}$ at $\mathrm{pH} 10$ redox potential in the reactors, especially in SL-BR2, due to the presence of polysulfide at a high concentration.

One of the very important parameters of the SOB biomass activity in the reactors is its $\mathrm{pH}$ response. Comparison of the two FBR reactors, run at different $\mathrm{pH}$ (9.5 for FBR1 and 8.8 for FBR2), demonstrated a different $\mathrm{pH}$ response (Fig. 2). There was a clear difference in the neutral part of the $\mathrm{pH}$ profiles for sulfide between the two reactors. This indicates either the presence of a separate $\mathrm{pH}$ neutral population in FBR2 (pH 8.8) or a dominance of facultatively alkaliphilic sulfide-oxidizing species in this reactor. The profile for polysulfide in FBR2 was similar to that of sulfide. In contrast, the profile for thiosulfate oxidation by FBR2 cells was typical for obligate alkaliphilic SOB. The latter profile might be due to the presence of different SOB populations specialized either in sulfide/ polysulfide or thiosulfate or due to a different $\mathrm{pH}$ response of the same population with different substrates. Our pure culture data favor the first suggestion. But, in general, the respiratory data clearly indicated domination of haloalkaliphilic SOB in the reactors.

A direct comparison of the membrane proteins, which are dominated by the respiratory enzymes, showed major similarity between the two reactors FBR1 and FBR2 (Fig. 3), suggesting a presence of the same dominant $\mathrm{SOB}$ population.

\section{DGGE analysis of the reactor biomass}

Molecular analysis of the biomass from two SL-BR and two FBR bioreactors based on 16S rRNA gene DGGE showed low genetic diversity, typical for autotrophic mix cultures with domination of one to two SOB genotypes and some side heterotrophic populations (Fig. 4). Since analysis of the SL-BR and FBR biomasses was performed on different gels, the profiles could not be directly compared.
Fig. 2 Influence of $\mathrm{pH}$ at $2 \mathrm{M}$ $\mathrm{K} / \mathrm{Na}$ on the respiratory activity of the washed cells from the reactors FBR1 and FBR2 with different sulfur substrates

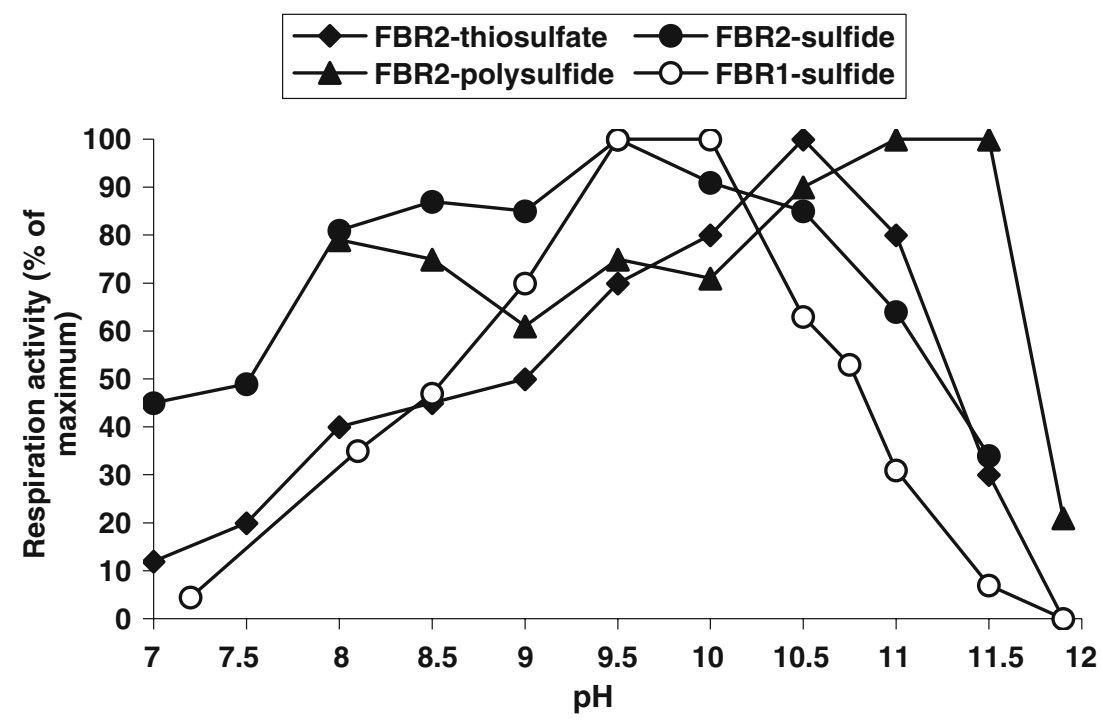


Fig. 3 Comparison of the membrane proteins from biomass in reactors FBR1 and FBR2, using SDS-PAGE (5-15\% gradient). Boxes show highly similar regions. Total protein concentration was $2 \mathrm{mg} \mathrm{mL}^{-1}$
Bioreactors

\section{Pure cultures}

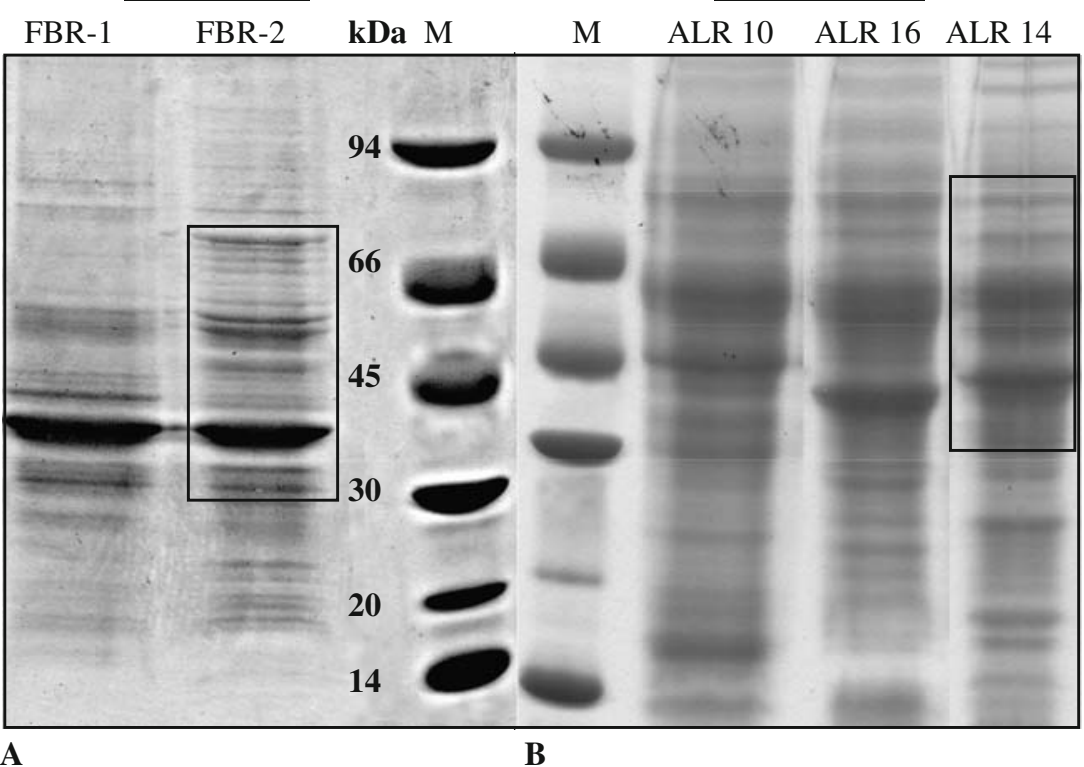

However, a general similarity of the FBR1 and FBR2 (pH difference 0.7 units) profiles were quite obvious, while the profiles of two SL-BR (difference in salinity is equivalent to $2 \mathrm{M} \mathrm{K} / \mathrm{Na}$ ) looked different. This might be explained by the fact that while $\mathrm{pH} 9.5$ and 8.8 are still within alkaliphilic range, a salt content of 1.5 and $3 \mathrm{M}$ total $\mathrm{Na} / \mathrm{K}$ usually selects for different groups of haloalkaliphilic SOB (Sorokin et al. 2006a). The phylogenetic analysis of the
DGGE band sequences demonstrated that in all samples, lithoautotrophic SOB belonging to the gamma-Proteobacteria were dominant (Fig. 5), although its affiliation differed at different reactor conditions. At moderate haloalkaline conditions (reactor SL-BR1), the dominant band belonged to a distant relative of the genus Halothiobacillus, while at higher salt (2-3 M K/Na), both in SL-BR2 and in FBR, the representatives of the genus Thioalkalivibrio were identi-
Fig. 4 DGGE analysis of the biomass from SL-BR (left, 35$70 \%$ gradient) and FBR (right, $20-70 \%$ gradient) bioreactors. For the comparison, three SOB isolates (ALR) from the FBR2 were also analyzed. Bands identification (by BLAST): 1 , 94\% similarity to Halothiobacillus kellyi; 2, 4, and 7, 99\% similarity to Thioalkalivibrio halophilus; $3,97 \%$ similarity to Marinospirillum alkaliphilum; 5 and $8,97 \%$ similarity to Bacillus agaradhaerans; $6,99 \%$ similarity to Alkalispirillum mobilis; 9, $99 \%$ to Paracoccus denitrificans
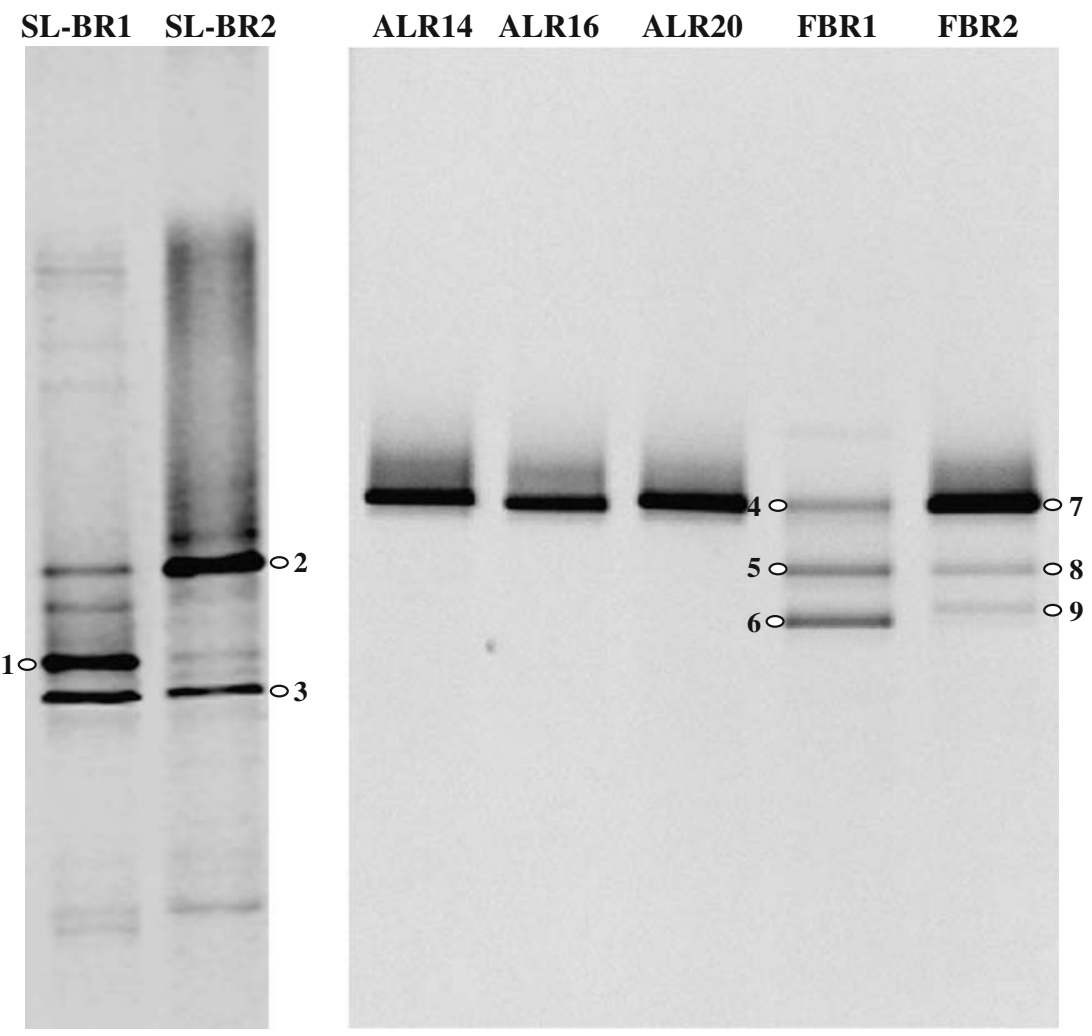
Fig. 5 Phylogenetic tree based on 16S rRNA gene sequencing, showing the position of the SOB identified by DGGE in the reactor biomass and of the pure cultures of haloalkaliphilic SOB isolated from the bioreactors. Sequences obtained in this work are in bold. Other undescribed strains, presented in the tree, were isolated from various soda lake sediments: AKL11, AKL15, and Tvmix90, from Kulunda Steppe (Siberia, Russia); ALMg14, from Mongolia; ALE20 and ALN 1, from Wadi Natrun (Egypt); ALJ24, from Lake Magadi (Kenya). Scale bar represents $1 \%$ sequence divergence

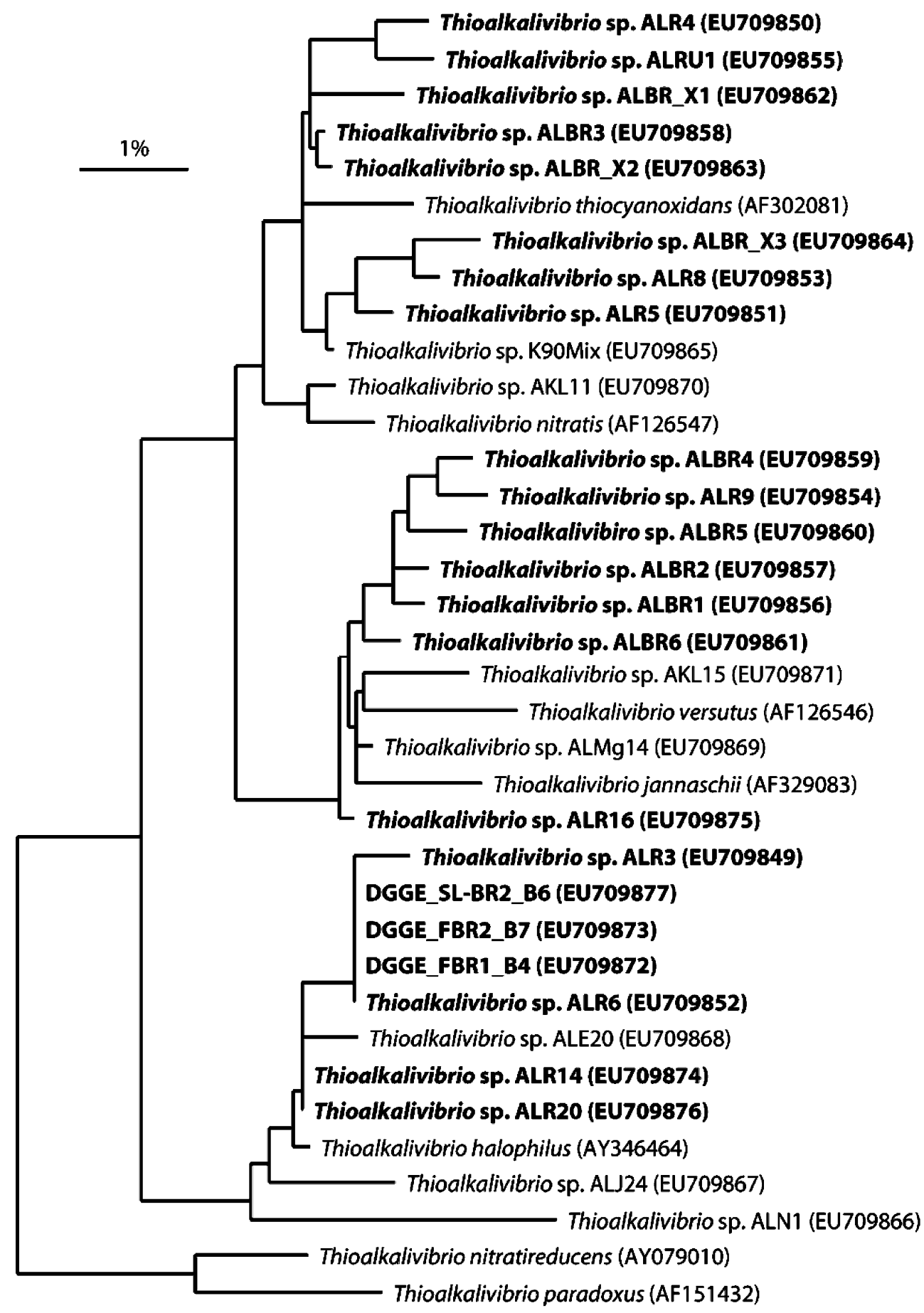

fied. Interestingly, in all three high-salt reactors, despite the difference in $\mathrm{pH}$, the $\mathrm{SOB}$ sequence was most closely related to the facultatively alkaliphilic and extremely salttolerant T. halophilus (Banciu et al. 2004b). Other identified sequences either belonged to nonsulfur-oxidizing alkaliphilic heterotrophs, such as Marinospirillum (SL-BR2) or Bacillus (FBR2), or to haloalkaliphilic facultative sulfur oxidizers, for which sulfide oxidation might provide additional energy (Sorokin et al. 2000, 2006b), such as Alkalispirillum (FBR1) and Rhobacteraceae (FBR2).
Isolation and identification of the dominant haloalkaliphilic SOB from the bioreactors

The cultivation approach demonstrated the presence of culturable SOB in the reactor biomass, mostly at a very high density (Table 1). From the highest positive dilution, more than 20 pure cultures were obtained either with thiosulfate or with sulfide as the sulfur substrate. All but one of them (strain ALR 15) were obligately chemolithoautotrophic SOB identified as the representatives of 
three subclusters within the genus Thioalkalivibrio by $16 \mathrm{~S}$ rRNA gene sequencing (Fig. 5). Most of the isolates from the SL-BR reactors $(\mathrm{pH} \mathrm{10)}$ and from the FBR run at $\mathrm{pH} 10$ were clustering around the core group of the genus which includes the type species Thioalkalivibrio versutus and its close relatives Thioalkalivibrio thiocyanoxidans, Thioalkalivibrio jannaschii, and Thioalkalivibrio nitratis, all obligate haloalkaliphiles. Only two isolates, ALR 3 and ALR 6, obtained from the high-pH FBR on sulfide, belonged to the cluster of facultative alkaliphilic halophile T. halophilus. On the other hand, all the isolates obtained with sulfide as substrate from the reactor with lowest $\mathrm{pH}$ (FBR2, $\mathrm{pH}$ 8.8) belonged to the $T$. halophilus subcluster, and only those enriched with thiosulfate clustered with the core group of obligate alkaliphiles. The latter results were consistent with the DGGE analysis (Figs. 4 and 5) of the biomass from FBR2 and with the $\mathrm{pH}$ profile of respiration (Fig. 2). On the other hand, the cultivation-based approach failed to produce the same results for SL-BR2, where molecular data also identified a dominance of a T. halophilus-like population, while only representatives of the core group of the genus Thioalkalivibrio were obtained in culture. This might be explained by the different culture conditions: In batch enrichment, cultivation at $\mathrm{pH} 10$ from the SL-BR2 might have provided better conditions for the secondary population of obligate alkaliphiles.

A pH-salt response of one of the T. halophilus-like isolates, strain ALR 14, was studied in more details, since this type seemed to be an important player in both types of bioreactors. Growth experiments with thiosulfate demonstrated that, despite being phylogenetically closely related to facultatively alkaliphilic T. halophilus, strain ALR 14 can be regarded as an obligate alkaliphile (Fig. 6a). On the other hand, its respiratory activity (Fig. 6b), especially with sulfide, was quite high already at subalkaline $\mathrm{pH}$ values (8.5-9.0), indicating good fitness to the reactor conditions $(\mathrm{pH} 8.8)$. Salt profiles corresponded to those of extremely salt-tolerant moderate halophiles (Fig. 6c) and also fit very well to the reactor conditions ( $2 \mathrm{M}$ total $\mathrm{Na} / \mathrm{K}$ ). An interesting $\mathrm{pH}$ effect was observed in case of the oxidation of sulfide and polysulfide by ALR 14 (Fig. 6d): The oxidation of sulfane atoms $\left(\mathrm{S}^{-}\right)$proceeded mostly to elemental sulfur at near neutral $\mathrm{pH}$, while its further oxidation to sulfate was increasing at an alkaline $\mathrm{pH}$ range. A similar effect of $\mathrm{pH}$ on product formation was found in the FBR bioreactors (van den Bosch et al. 2008), with one important difference: In case of washed cells of a pure culture, the final oxidation product was sulfate, while in the bioreactor, thiosulfate accumulated at high $\mathrm{pH}$. This difference can be accounted to the nature of sulfane atom oxidation in the two systems. In the bioreactors, enzymatic oxidation of polysulfide sulfane atoms was apparently inhibited by very low redox potentials, resulting in spontaneous oxidation to thiosulfate. In contrast, the washed cells experiment was conducted at a high initial oxygen concentration, allowing enzymatic conversion of sulfane with sulfate as the final product.

A single heterotrophic isolate was obtained from FBR2 from the special colonies formed on alkaline plates incubated under the $\mathrm{H}_{2} \mathrm{~S}$-containing gas phase. Since also DGGE analysis indicated a presence of heterotrophs in the reactor, there must be a source of organic carbon in the system. Such carbon could be provided by a dominant population of Thioalkalivibrio either by excretion or after lysis of dead cells. Usually, SOB are forming sulfur inside the colonies. In contrast, strain ALR 15 produced large sulfur halos around the colonies (Supplementary Fig. 2). Further investigation showed that the bacterium, which was identified as a member of the genus Halomonas, was an obligate heterotroph unable to actually use sulfide or thiosulfate as an energy source. However, during heterotrophic growth, it oxidized thiosulfate to tetrathionate, which is a well-known property of this group of gammaProteobacteria (Sorokin 2003). Our scenario to explain this extracolonial sulfur formation is the following (Supplementary Fig. 2): $\mathrm{H}_{2} \mathrm{~S}$ was being absorbed into the alkaline agar from the gas phase and partially converted to elemental sulfur. The latter reacted with sulfide to form polysulfide (indeed a yellowish coloration was observed after prolonged incubation of the plates). Spontaneous reaction of polysulfide with oxygen resulted in the formation of thiosulfate. In this reaction, the active role of the bacterium starts, in providing tetrathionate - a powerful oxidant for sulfide. The reaction of sulfide with tetrathionate produces sulfur and regenerates the substrate (thiosulfate) for the heterotroph. So, only traces of thiosulfate are necessary to catalyze the oxidation of sulfide to sulfur in the presence of tetrathionate-forming heterotrophs. Such a microbiochemical catalysis has been demonstrated for a marine heterotrophic bacterium Catenococcus (Sorokin et al. 1996). The difference with Halomonas ALR 15 is in the internal generation of thiosulfate from polysulfide, which is stable only at highly alkaline conditions. In the case of Catenococcus, thiosulfate had to be supplied externally. Although the colonies with external sulfur accumulation were quite common in our enrichments, this organism was not found in the reactor biomass by molecular analysis, which makes its role in sulfide oxidation in situ in comparison with the obligate autotrophic Thioalkalivibrio questionable.

\section{Discussion}

Our previous microbiology investigation of various soda lakes demonstrated a presence of highly diverse population of the obligately lithoautotrophic SOB of the genus Thioalkalivibrio which was dominating especially at ex- 

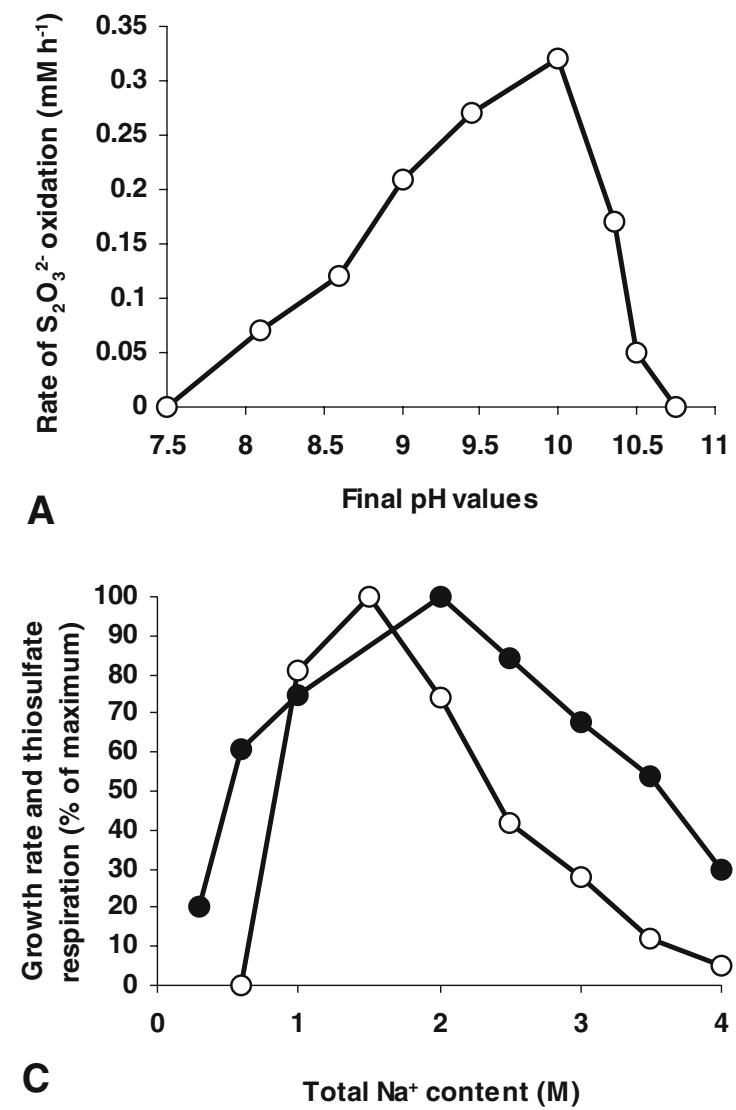

Fig. $6 \mathrm{pH}-$ salt response of Thioalkalivibrio strain ALR 14 isolated from the sulfide-oxidizing bioreactor. a $\mathrm{pH}$ influence on growth with thiosulfate. $\mathbf{b} \mathrm{pH}$ profile for oxidation of different sulfur compounds by washed cells grown at $2 \mathrm{M}$ total $\mathrm{Na}^{+}, \mathrm{pH} 10$ with thiosulfate (open circles, thiosulfate; closed circles, sulfide; open triangles, polysulfide; closed triangles, sulfur). c Salt profile for thiosulfate oxidation at $\mathrm{pH}$

treme salinity (Sorokin, Kuenen 2005; Sorokin et al. 2006a; Foti et al. 2006). So, it is not surprising that in the bioreactors inoculated with the sediments from hypersaline soda lakes, these haloalkaliphilic SOB species were dominating. The reactor isolates were very closely related to the Thioalkalivibrio species obtained from the natural sediments isolated at fully oxic conditions with thiosulfate as substrate. This might mean that both low-potential oxidation of sulfide/polysulfide and high-potential thiosulfate oxidation pathway may coexist in the same SOB species. Indeed, that's what usually can be seen in the respiratory profiles of the haloalkaliphilic SOB grown either with thiosulfate or sulfide at fully aerobic conditions, i.e., equal rates of sulfide- and thiosulfate-dependent respiration. On the other hand, the respiratory tests with the SOB biomass from the low redox potential bioreactors clearly indicated sulfide/polysulfide preference (see Fig. 1), suggesting a possibility of a different pathway for oxidation of these highly reduced electron donors as compared to thiosulfate oxidation. One of the specialized components of such a pathway might be sulfide-quinone reductase-a
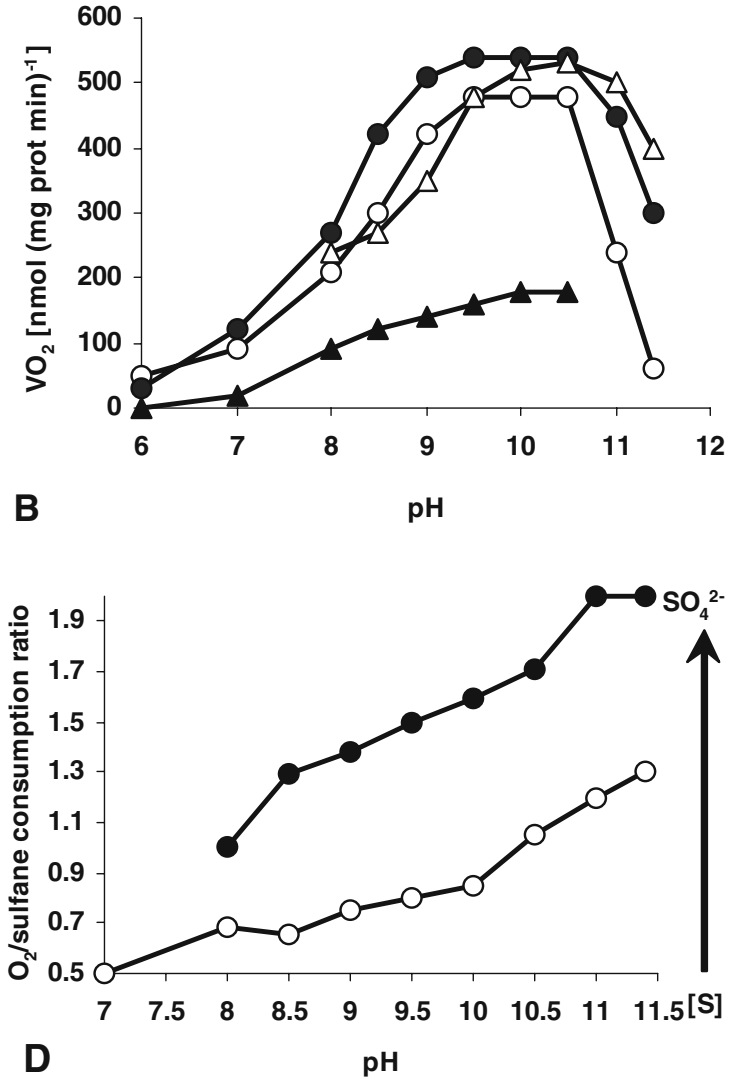

10 in cultures (open circles) and by washed cells pregrown at $2 \mathrm{M}$ total $\mathrm{Na}^{+}$(closed circles). d Influence of $\mathrm{pH}$ on product formation during oxidation of sulfide (open circles) and polysulfide-sulfane (closed circles) by washed cells at $2 \mathrm{M} \mathrm{Na}^{+}$; the arrow indicates a shift in the product formation from sulfur to sulfate with increasing $\mathrm{pH}$

flavin-containing enzyme oxidizing sulfide to elemental sulfur with quinones as electron acceptors (Griesbeck et al. 2000), which activity was detected in the reactor biomass. Furthermore, the profound "sulfide/polysulfide specialization" of the biomass in SL-BR2 and FBR1 correlated with a relatively low cytochrome $c$ oxidase activity. Taken together, this might indicate a substantial change in the electron flow pathway and needs further, more detailed investigation.

Another interesting result of this study is a diversity of a single culturable haloalkaliphilic SOB taxon found in the bioreactors at triple extreme conditions (high alkalinity, high total salt, high K). Although all of them belonged to a single genus, most of the isolates were genetically different from each other. The exact meaning of such difference is not completely clear, although some phenotypic difference, such as correlation with the $\mathrm{pH}$ in the reactor and with the substrate, used for isolation, can be seen in different subgroups. Apparently, the genus Thioalkalivibrio, despite being a relatively narrow specialized ecotype, possesses extraordinary potential for microadaptation. On the other 
hand, the molecular analysis (DGGE) of the reactor populations indicated a presence of a single Thioalkalivibrio phylotype closely related to a facultatively alkaliphilic species T. halophilus. It is not easy to explain such a big difference between the results from two approaches. We can offer two. First, this could be a result of cultivation bias, since batch enrichment/isolation from the SL-BR reactors was performed at $\mathrm{pH} 10$ and resulted in isolation of numerous strains of obligate alkaliphiles related to the core group of the genus Thioalkalivibrio. Perhaps, if lower $\mathrm{pH}$ values were used, isolates related to T. halophilus would be obtained at least with sulfide as the substrate, similar to the results with FBR reactors. A second explanation might be that the DNA from the obligately alkaliphilic types of Thioalkalivibrio, for one or another reason, was less accessable for PCR - a usual bias of the DGGE method. Judging from the previous results of the microbiological study of natural alkaline lakes, the major factor determining a domination of these two types of Thioalkalivibrio is $\mathrm{pH}$ in combination with high chloride content. For example, $T$. halophilus - like SOB - dominated among the isolates from the haloalkaline Wadi Natrun lakes in Egypt with $\mathrm{NaCl}$ as a dominant salt and $\mathrm{pH}$ around 9, while natrono (soda)philic Thioalkalivibrio species dominated in true soda lakes with $\mathrm{pH}$ around 10 where sodium carbonates were present at molar concentration (Sorokin et al. 2006a).

The genus Thioalkalivibrio has a great potential to thrive at extremely haloalkaline conditions and is a sure candidate for application in biological sulfide removal directly from spent sulfide caustics. In the natural soda lake sediments, often another genus of low salt-tolerant alkaliphilic SOB (Thioalkalimicrobium) can be found, which is characterized by extremely high rates of sulfide oxidation (Sorokin and Kuenen 2005; Sorokin et al. 2006a). The fact that it apparently was not present in the described bioreactors could probably be explained by high salt concentration which is above its capacity to grow.

Acknowledgements This work was supported by STW (WBC.5939) and NWO-RFBR (47.011.2004.010) with a financial contribution from Shell Intertnational and Paque B.V. (The Netherlands).

Open Access This article is distributed under the terms of the Creative Commons Attribution Noncommercial License which permits any noncommercial use, distribution, and reproduction in any medium, provided the original author(s) and source are credited.

\section{References}

Banciu H, Kleerebezem R, Muyzer G, Kuenen JG, Sorokin DY (2004a) Application of haloalkaliphilic sulfur-oxidizing bacteria for the removal of $\mathrm{H}_{2} \mathrm{~S}$ from gas streams. In: Verstraete $\mathrm{W}$ (ed) European Symposium on Environmental Biotechnology, ESEB 2004, Proceedings, Oostende, Belgium, April 25-28, 2004, pp 345-348

Banciu H, Sorokin DY, Muyzer G, Kleerebezem R, Galinski EA, Kuenen JG (2004b) Thioalkalivibrio halophilus sp. nov, a novel obligately chemolithoautotrophic facultatively alkaliphilic and extremely salt-tolerant sulfur-oxidizing bacterium from a hypersaline alkaline lake. Extremophiles 8:325-334

Buisman CJN, Geraarts BG, IJspeert P, Lettinga G (1990) Optimization of sulphur production in a biotechnological sulphideremoving reactor. Biotechnol Bioeng 35:50-56

Foti M, Ma S, Sorokin DYu, Rademaker JLW, Kuenen JG, Muyzer G (2006) Genetic diversity and biogeography of haloalkaliphilic sulfur-oxidizing bacteria belonging the genus Thioalkalivibrio. FEMS Microbiol Ecol 56:95-101

Griesbeck C, Hauska G, Schütz M (2000) Biological sulfide oxidation: sulfide-quinone reductase (SQR), the primary reaction. In: Pandalai SG (ed) Recent research developments in microbiology. vol. 4. Research Signpost, Trivadrum, India, pp 179-203

Janssen AJH, Sleyster R, Van der Kaa C, Jochemsen A, Bontsema J, Lettinga G (1995) Biological sulfide oxidation in a fed-batch reactor. Biotechnol Bioeng 47:327-333

Janssen AJH, Lettinga G, de Keizer A (1999) Removal of hydrogen sulfide from wastewater and waste gases by biological conversion to elemental sulfur. Colloidal and interfacial aspects of biologically produced sulfur particles. Colloids Surf A Physicochem Eng Asp 151:389-397

Laemmli UK (1970) Cleavage of structural proteins during the assembly of the head of bacteriophage T4. Nature 227:680-685

Ludwig W, Strunk O, Westram R, Richter L, Meier H, Yadhukumar, Buchner A, Lai T, Steppi S, Jobb G, Forster W, Brettske I, Gerber S, Ginhart W, Gross O, Grumann S, Hermann S, Jost R, Konig A, Liss T, Lûmann R, May M, Nonhoff B, Reichel B, Strehlow R, Stamatakis A, Stuckmann N, Vilbig A, Lenke M, Ludwig T, Bode A, Schleifer KH (2004) ARB: a software environment for sequence data. Nucleic Acids Res 32:13631371

Muyzer G, de Waal EC, Uitterlinden A (1993) Profiling of complex microbial populations by denaturing gradient gel electrophoresis analysis of polymerase chain reaction-amplified genes coding for 16S rRNA. Appl Environ Microbiol 59:695-700

Pfennig N, Lippert KD (1966) Über das Vitamin $\mathrm{B}_{12}$ bedürfnis phototropher Schwefel bacterien. Arch Microbiol $55: 245-256$

Schafer H, Muyzer G (2001) Denaturing gradient gel electrophoresis in marine microbial ecology. In: Paul JH (ed) Methods in microbiology. Academic, New York

Sorokin DY (2003) Oxidation of inorganic sulfur compounds by obligately organotrophic bacteria. Microbiology (Moscow, English Translation) 72:641-653

Sorokin DY (2008) Diversity of halophilic sulfur-oxidizing bacteria in hypersaline habitats. In: Dahl C, Friedrich CG (eds) Microbial sulfur metabolism. Proceedings of the International Symposium on Microbial Sulfur Metabolism 29.06.-02.07.2006, Münster, Germany. Springer, Berlin, pp 225-237

Sorokin DY, Kuenen JG (2005) Haloalkaliphilic sulfur-oxidizing bacteria in soda lakes. FEMS Microbiol Rev 29:685-702

Sorokin DY, Kuenen JG, Jetten M (2001) Denitrification at extremely alkaline conditions in obligately autotrophic alkaliphilic sulfuroxidizing bacterium Thioalkalivibrio denitrificans. Arch Microbiol 175:94-101

Sorokin DY, Robertson LA, Kuenen JG (1996) Sulfur cycling in Catenococcus thiocyclus. FEMS Microbiol Ecol 19:117-125 
Sorokin DY, Tourova TP, Kuznetsov BB, Bryantseva IA, Gorlenko VM (2000) Roseinatronobacter thiooxidans gen. nov., sp.nov.a new alkaliphilic aerobic bacteriochlorophyll $a$-containing bacterium from soda lake. Microbiology (Moscow, English Translation) 69:1-9

Sorokin DY, Banciu H, Robertson LA, Kuenen JG (2006a) Haloalkaliphilic sulfur-oxidizing bacteria. In: Dworkin M, Falkow S, Rosenberg E, Schleifer KH, Stackebrandt E (eds) The prokaryotes: ecophysiology and biochemistry. vol. 2. Springer, New York, pp 969-984

Sorokin DY, Zhilina TN, Spiridonova EM, Tourova TP, Lysenko AM (2006b) Increased metabolic versatility of haloalkaliphilic bacte- ria belonging to the Alkalispirillum-Alkalilimnicola group from soda lakes. Extremophiles 10:213-220

Van den Bosch PLF, van Beusekom OC, Buisman CJN, Janssen AJH (2007) Sulfide oxidation at halo-alkaline conditions in a fedbatch bioreactor. Biotechnol Bioeng 97:1053-1063

Van den Bosch PLF, Sorokin DY, Buisman CJN, Janssen AJH (2008) The effect of $\mathrm{pH}$ on thiosulfate formation in a biotechnological process for the removal of hydrogen sulfide from gas streams. Env Sci Technol 42:2637-2642

Visser JM (1997) Sulfur compound oxidation and sulfur production by Thiobacillus sp. W5 (now-Halothiobacillus). Ph.D. thesis, TU Delft, Delft, The Netherlands 